\title{
LA IMPLANTACIÓN DEL 'VOTO ROGADO' EN ESPAÑA: EL PERJUDICIAL LÍMITE A LA PARTICIPACIÓN ELECTORAL DE LOS ESPAÑOLES RESIDENTES EN EL EXTRANJERO A PUNTO DE ENMENDARSE ${ }^{1}$
}

\author{
JOSÉ LUIS MATEOS CRESPO \\ Investigador de Derecho Constitucional \\ Universidad de Salamanca
}

\begin{abstract}
SUMARIO
I. Introducción. II. Vínculo entre nacionalidad, ciudadanía y Constitución. III. El incremento de las garantías del voto en el origen de la generalización del voto rogado en el exterior. IV. La incidencia en la participación de los españoles residentes- ausentes tras la reforma. V. La contrarreforma como única opción para paliar los efectos perjudiciales del voto rogado en el exterior. V. Pronunciamientos del tribunal Constitucional. VI. Conclusiones.
\end{abstract}

\section{INTRODUCCIÓN}

En 2011 se aprobaron de forma simultánea dos reformas en la legislación electoral a través de sendas leyes orgánicas, pero tan sólo una de ellas ha resultado pacífica con el paso de los años. La reforma que mayor rechazo ha generado en los sucesivos comicios electorales ha sido la llevada a cabo por la LO 2/2011, en lo referente a la modificación del artículo 75 de la LOREG. Esta reforma extendió a las elecciones generales el denominado voto rogado para los españoles residentes ausentes en el extranjero - integrantes del Censo de Españoles Residentes Ausentes (CERA) — , vigente en las elecciones municipales con anterioridad a 2011.

La incorporación generalizada del voto rogado ha arrojado cifras preocupantes en torno a la participación electoral. Desde 2011, se han celebrado elecciones

1 Estando en pruebas este trabajo se han disuelto las Cámaras (RD 129/2019, de 4 de marzo) impidiendo la derogación del voto rogado. 
generales en los años 2011, 2015 y 2016, así como municipales y autonómicas en 2015; y en todas ellas la participación de los españoles en el extranjero ha descendido de forma notable, a pesar del incremento de electores inscritos en el CERA. Es indudable, por tanto, que esta reforma ha limitado de hecho el ejercicio del derecho fundamental a la participación política, de modo que la intencionalidad primigenia del legislador para incrementar las garantías en la emisión del voto desde el extranjero, ha fracasado por los perjudiciales efectos provocados.

La principal intención de este trabajo es contribuir al debate tanto doctrinal como social y político en torno a la participación electoral de los españoles en el extranjero en general, y al voto rogado en particular, realizando un análisis lo más sistemático posible; con esta finalidad, se acudirá al Derecho comparado y a lo dicho por el TC. De igual modo, se plantearán propuestas de mejora en el actual sistema con el objetivo de incrementar las garantías en el ejercicio del derecho al voto y permitir mayores cotas de participación electoral, asegurando en todo caso el encaje de todas las propuestas en nuestro marco constitucional.

\section{VÍNCULO ENTRE NACIONALIDAD, CIUDADANÍA Y CONSTITUCIÓN}

La cuasi identidad conceptual entre nacionalidad y ciudadanía es «resultado de un proceso histórico de construcción que ha concluido con la pérdida del estatuto privilegiado de ciertas categorías de individuos», de forma que la extensión del sufragio universal ha supuesto que, en la actualidad, tan sólo la edad y determinadas causas legalmente establecidas - los límites naturales de los que hablaba Kelsen ${ }^{2}$ - , son los factores de exclusión del derecho de sufragio de los naciona$\mathrm{les}^{3}$. En este proceso, a medida que los súbditos se convirtieron en soberanos «la ciudadanía pasa a ser el instituto jurídico imprescindible que recoge las condiciones subjetivas necesarias para esa conversión, así como el haz de derechos en los que se ha de plasmar la participación en el ejercicio del poder de una comunidad, consustancial a la soberanía democrática» ${ }^{4}$. La pertenencia individual al «pueblo» de un determinado Estado-nación como sujeto colectivo en tanto nacional y a la comunidad política como miembro con derechos subjetivos — tales como el de participación es, en buena medida, equiparable-. Además, «el moderno concepto de ciudadanía habría nacido de la mano del de nacionalidad como el concreto contenido jurídico-participativo que se anuda a la pertenencia del individuo a la comunidad, y tiende, en la actual era posnacional, a desvincular su base

2 Kelsen, H., Esencia y valor de la Democracia, Labor, Barcelona, 1934, p. 33.

3 Santolaya Machetti, P., Díaz Crego, M., El sufragio de los extranjeros. Un estudio de Derecho comparado, Cuadernos y Debates, n. ${ }^{\circ} 183$, CEPC, Madrid, 2008, pp. 11 y ss.

4 Aláez Corral, B., «Nacionalidad y ciudadanía ante las exigencias del Estado constitucional democrático», REP (Nueva época), n. ${ }^{\circ} 127,2005$, p. 135. 
teórica de la de la nacionalidad y a crear diferentes niveles de pertenencia a la comunidad (política, social, económica, cultural, etc.) ligados a la titularidad de diferentes grupos de derechos fundamentales» ${ }^{5}$. En este escenario, los nacionales están vinculados con mayor intensidad al ejercicio de la participación política en la comunidad ${ }^{6}$, lo que así ocurre por ejemplo con el derecho al sufragio, que se reconoce en el ordenamiento jurídico español de forma más amplia a los nacionales, ya sean o no residentes en territorio nacional, pero no así a los residentes no nacionales, que sólo en determinados supuestos ven reconocido el derecho de sufragio y no en todo tipo de elecciones; esto es: el grado de ciudadanía en torno al derecho de sufragio como parte del derecho de participación política es mayor para los nacionales ${ }^{7}$.

Si bien, el pueblo en quien reside la soberanía nacional no es identificable al conjunto de todos los ciudadanos, ni siquiera aunque participaran todos ellos, se podría asegurar que no lo hicieron en ejercicio de su soberanía individualmente considerada, sino en el de la soberanía del pueblo/nación; por lo que es posible, además, diferenciar titularidad y ejercicio de la soberanía ${ }^{8}$, siendo el mecanismo de la representación un artificio consustancial a la idea de soberanía nacional/popular. Además, acudiendo a las palabras de Espósito: «el contenido de la democracia no radica en que el pueblo tenga la titularidad de la soberanía, que prácticamente no es nada, sino su ejercicio, que prácticamente lo es todo» ${ }^{10}$, nos permite sostener que de nada sirve el reconocimiento formal de la titularidad del derecho de sufragio a los nacionales residentes en el exterior, si de forma efectiva no se posibilita su ejercicio ${ }^{11}$.

La exclusión del ejercicio del derecho al sufragio activo, pero conservando su titularidad, a los nacionales que no residen de forma habitual en el país de su nacionalidad y tampoco tengan reconocido el ejercicio del derecho político al sufragio en el país de residencia, produciría un efecto ciertamente inusual, convirtiendo a estos ciudadanos en verdaderos «apátridas del derecho de participar en la toma de decisiones tanto de su comunidad nacional como de su comunidad

5 Ibidem, p. 139.

6 Ibidem, p. 147.

7 ALÁEZ CORRAL señala que «La nacionalidad y la ciudadanía van a servir para medir respectivamente el mayor o menor grado de sujeción del individuo a dicho ordenamiento constitucional y su mayor o menor grado de participación social», «Nacionalidad, ciudadanía y democracia en la configuración de la nación/pueblo», Fundamentos: Cuadernos monográficos de teoría del estado, derecho público e historia constitucional, n. ${ }^{\circ}$ 7, 2012, p. 90 .

8 Es interesante en este punto remitirnos a la obra de BASTIDA Freijedo, F.J., «La soberanía borrosa: la Democracia», Fundamentos: Cuadernos monográficos de teoría del estado, derecho público e historia constitucional, n. ${ }^{\circ} 1,1998$, pp. 381-460.

9 Bastida Freijedo, F.J., «Elecciones y Estado democrático de Derecho», REDC, n. ${ }^{\circ} 32,1991$, p. 119. Del mismo autor, «Constitución, soberanía y democracia», RCEC, n. ${ }^{\circ}$ 8, 1991, p. 12.

10 Bastida Freijedo, F.J., op, cit., «Elecciones y Estado democrático de Derecho», p. 125.

11 Arnaldo Alcubilla, E., El derecho de sufragio de los emigrantes en el ordenamiento español, CEC, Madrid, 1995, p. 47. 
de residencia ${ }^{12}$. Además, el hecho de dividir en función de su lugar de residencia al cuerpo electoral del pueblo perteneciente a un mismo Estado en tanto nacionales, sería más propio de la teoría del electorado-función ${ }^{13}$ y un claro caso de discriminación ${ }^{14}$. Con lo cual, esta opción queda absolutamente descartada, al menos por nuestra parte.

En nuestro texto constitucional, el poder soberano reside en todos y cada uno de los nacionales españoles con independencia de su lugar de residencia, incluyendo por tanto a los nacionales residentes en el extranjero (art. 1.2 CE). Resulta conveniente, además, relacionar el mencionado poder soberano del pueblo español con el derecho fundamental a la participación política (art. $23 \mathrm{CE}$ ) y el reconocimiento como electores y elegibles a todos los españoles en pleno uso de sus derechos políticos, así como indicar que el Estado debe «facilitar el ejercicio del derecho de sufragio a los españoles que se encuentren fuera del territorio de España» (art. 68.5 CE) que, a su vez, se conecta con lo dispuesto en el artículo 42 CE. En síntesis: «sólo los españoles tienen derecho a participar y a elegir a los representantes nacionales en el Parlamento y a ser elegidos para formar parte de los diferentes poderes del Estado» ${ }^{15}$. Así, consideramos que la participación de los ciudadanos-nacionales —en este caso, españoles - en la elección de sus representantes a través de canales auténticos, institucionalizados y representativos, es la auténtica esencia de la democracia ${ }^{16}$.

El reconocimiento expreso en la Constitución de 1978 del derecho de sufragio a los españoles residentes fuera del territorio nacional en el artículo 68.5 $\mathrm{CE}^{17}$ es una novedad en nuestra historia constitucional con explicación en la incidencia del fenómeno migratorio durante la dictadura franquista, por influencia del texto portugués y con reflejo en otros como el italiano. Existen dudas sobre si lo establecido en el artículo 68.5 CE vincula directamente a los poderes públicos, por las dificultades técnicas para garantizar este derecho a todos los españoles residentes en el extranjero ${ }^{18}$. No obstante, el mandato del artículo 9.2 CE obliga a los poderes públicos a remover los obstáculos para que los españoles ejerzan, entre otros, su derecho fundamental a la participación política ${ }^{19}$, por lo

12 Arnaldo Alcubilla, E., op. cit., p. 49.

13 «Como diría Duverger, la noción del electorado-función por la que sólo un grupo tiene reconocida la misión de querer por toda la nación, no representando a sus electores ni a su circunscripción, sino que el conjunto de diputados representa a toda la nación». En García CANALES, M., La teoría de la representación en la España del siglo xx, Publicaciones del Departamento de Derecho Político, Murcia, 1977, p. 95.

14 Arnaldo Alcubilla, E., El derecho de sufragio de los emigrantes en el ordenamiento español, CEPC, Madrid, 1995, p. 54

15 Rubio Castro, A., Moya Escudero, M., «Nacionalidad y ciudadanía: una relación a debate», Anales de la Cátedra Francisco Suárez, n. ${ }^{\circ}$ 37, 2003, p. 108.

16 Ramírez Jiménez, M., La participación política, Tecnos, Madrid, 1985, p. 32.

17 Arnaldo Alcubilla, E., op. cit., pp. 272-287.

18 Alzaga Villaamil, O., La Constitución española de 1978. Comentario sistemático, Ediciones del Foro, Madrid, 1978, p. 472.

19 Arnaldo Alcubilla, E., op. cit., p. 281. 
que el contenido del artículo 68.5 CE es vinculante para los poderes públicos, aun cuando existan las mencionadas dificultades técnicas en la práctica.

Ahora bien, el escenario no ha permanecido inmutable en las últimas décadas, de modo que el derecho de sufragio se ha ido extendiendo considerablemente, incluyendo cada vez más la participación de no nacionales en procesos electorales tales como elecciones municipales, primando la residencia sobre la nacionalidad, lo que ha supuesto una «progresiva disociación entre nacionalidad y ciudadanía» ${ }^{20}$ y recelos por el menoscabo en la soberanía nacional debido a la intervención en la formación de decisiones políticas de nacionales de otro Estado ${ }^{21}$. En este sentido, la integración de España en la Unión Europea y la firma de tratados tales como el de Maastricht y restante normativa comunitaria, han configurado la «ciudadanía europea» ${ }^{22}$ con repercusión en el ejercicio de derechos fundamentales por parte de los ciudadanos de países miembros de la Unión Europea.

\section{EL INCREMENTO DE LAS GARANTÍAS DEL VOTO EN EL ORIGEN DE LA GENERALIZACIÓN DEL VOTO ROGADO EN EL EXTERIOR}

El legislador incorporó a través de una modificación de la LOREG nuevos condicionantes para el ejercicio del derecho al sufragio por los españoles residentes en el extranjero, lo que ha producido efectos en la participación electoral, ya advertidos por la JEC en su informe de 2009. La intención principal de la reforma legal fue incrementar las garantías en la emisión del voto desde el extranjero, al haberse detectado irregularidades en diferentes elecciones celebradas con anterioridad. No obstante, hay parte de la doctrina que defiende el reconocimiento de la participación en los procesos de tomas de decisión sólo a los destinatarios de las mismas, excluyendo a aquéllos que han perdido el vínculo real con el ámbito geográfico al haber trasladado su residencia y que, de forma efectiva, no son destinatarios de las decisiones, si bien nuestra Constitución les reconoce su participación por mantener vivo el vínculo de la nacionalidad ${ }^{23}$.

Como premisa, además de lo ya indicado, es necesario señalar que toda reforma de la legislación electoral tiene un leitmotiv y, en bastantes ocasiones, razones más o menos transparentes por parte de quienes las promueven y llevan a

20 Presno Linera, M.A., «El voto de los extranjeros en España y el voto de los españoles residentes en el extranjero. A propósito del Informe del Consejo de Estado sobre las propuestas de modificación del Régimen Electoral General», REDC, n. ${ }^{\circ}$ 87, 2009, p. 186.

21 Ibídem, p. 189.

22 MaAs, W., «La creación y la evolución de la ciudadanía europea», Panorama social, n. ${ }^{\circ}$ 17, 2013, pp. 9-19.

23 Presno Linera, M.A., op. cit., p. 209. 
cabo. En este sentido, «ninguna reforma electoral es inocente ni neutral» ${ }^{24}$, siendo los intereses de los partidos políticos la variable explicativa de la configuración de un concreto sistema electoral que, por lo general, buscan el mantenimiento del status quo. Así mismo, cualquier «pequeña y aparentemente inocua modificación puede dar al traste con un edificio construido mediante complejos equilibrios, ajustes de cargas y de tensiones perfectamente previstos» ${ }^{25}$. En esta ocasión, la principal motivación para la reforma legal objeto de este trabajo fue, como se ha indicado, incrementar las garantías del voto en el exterior, lejos de las especulaciones suscitadas en el debate político a posteriori en torno al interés que determinadas formaciones políticas tuvieran para dificultar el voto de los españoles residentes en el extranjero y cuyos votos pudieran no ser favorables a las mismas, por tratarse de meras conjeturas sin base alguna para siquiera considerar a éste como el principal motivo de la reforma para generalizar el voto rogado.

Ciertamente, con la regulación del voto en el exterior previa a la modificación de 2011, bastaba con una copia del pasaporte y un garabato ilegible para que los partidos políticos pusieran en marcha su maquinaria dirigida a solicitar a la Junta Electoral el envío a una dirección concreta del certificado censal como residente ausente $^{26}$. La facilidad con que se podía emitir el voto por persona distinta del votante «habida cuenta de la falta de recepción personal de la documentación» ${ }^{27}$, favorecía la aparición de supuestos de manipulación y suplantación de la identidad de electores, lo que motivó algunas denuncias por fraude del procedimiento.

El origen parlamentario de la LO 2/2011 se encuentra en los trabajos de la Subcomisión de la Comisión Constitucional creada para el estudio de la reforma electoral sobre la base del Informe del Consejo de Estado y de la JEC, ambos de 2009. Estos trabajos y las conclusiones dieron como resultado la presentación de una Proposición de Ley $^{28}$ en 2010, por los GGPP Socialista, Popular, Catalán (la extinta Convergència i Unió-CiU) y Vasco (EAJ-PNV), que, entre otros aspectos más técnicos, destacaban: la modificación del art. 75 LOREG introduciendo el conocido como voto a instancia de parte o rogado, el voto en urna en el exterior y la supresión del artículo $190 \mathrm{LOREG}^{29}$. La tramitación parlamentaria de esta

24 Reviriego Picón, F., «Las reformas electorales y la magnitud de las circunscripciones», Estudios de Deusto, vol. 63, n. ${ }^{\circ} 2,2015$, p. 193.

25 Ripollés Serrano, M.R., «La nueva regulación del derecho al voto de los españoles que se encuentran en el extranjero, especial consideración al CERA tras la reforma de la LOREG por la LO 2/2011», Estudios sobre la Reforma de la Ley Orgánica del Régimen Electoral General: la Reforma continua y discontinua, (Dirs. Álvarez Conde, E. y López De Los Mozos Díaz, A.), p. 203, IDP, Madrid, 2011.

26 Pauner Chulvi, C., «Reflexiones constitucionales sobre la propuesta limitativa del derecho de sufragio activo de los emigrantes», Corts: Anuario de derecho parlamentario, n. ${ }^{\circ} 19,2007$, p. 190.

27 GÁlvez MuÑoz, L., «El sistema de votación español a la luz de la Constitución», REDC, n. ${ }^{\circ}$ 87, 2009, p. 96.

28 BOCG-B, CD, 22 de octubre de 2010, n. ${ }^{\circ} 282-1$.

29 El art. 190 de la LOREG, derogado en 2011, ya establecía la obligatoriedad de comunicar a la correspondiente Delegación Provincial de la Oficina del Censo Electoral su deseo para ejercer el voto en las elecciones del municipio donde estuvieran inscritos, esto es, el voto rogado. 
Proposición de Ley se hizo paralelamente con otra proposición de la misma naturaleza que dio lugar a la LO 3/2011, que fue presentada por los GGPP Socialista y Popular $^{30}$, con el objetivo de endurecer la participación electoral del entorno político de la banda terrorista ETA.

Tras su aprobación y entrada en vigor, los españoles residentes-ausentes en el extranjero actualmente no tienen derecho al voto en las elecciones municipales tras la supresión del art. 190 LOREG, ni tampoco pueden ser elegidos en virtud del art. 6.1 LOREG, que determina la elegibilidad únicamente de quienes ostenten la cualidad de electores, es decir, los que figuren en el Censo de Españoles Residentes en España — art. 2.3 LOREG_- Por tanto, desde 2011, los residentes-ausentes no tienen reconocido el derecho al sufragio activo ni al sufragio pasivo $^{31}$ en las elecciones municipales (Acuerdo JEC n. . 21/2011). Así las cosas, en comicios locales, el legislador ha primado la vecindad sobre la nacionalidad como criterio a la hora de reconocer el derecho de sufragio de los electores, prevaleciendo el binomio vecino-elector al de nacional-elector. Esto es así, además, por la interpretación del art. 140 CE, que determina la elección de los alcaldes por los concejales o por los vecinos.

La eliminación del sufragio para los españoles residentes en el extranjero en los comicios locales, vía supresión del art. 190 LOREG, fue resultado de las recomendaciones del Informe del Consejo de Estado y de los debates en la Subcomisión sobre las posibles modificaciones del Régimen Electoral General, teniendo reflejo en el acuerdo sobre el Informe emitido por ésta ${ }^{32}$. En su mayoría, los cambios legislativos en torno al régimen electoral fruto del trabajo de la Subcomisión fueron unánimes, excepto en lo referente al voto emigrante, especialmente en torno a la derogación del voto en las elecciones municipales. No obstante, otros grupos se apoyaron en la postura del Consejo de Estado que declaraba discutible la participación de los españoles ausentes en la elección de las corporaciones locales, una adscripción basada en una ficción; si bien es cierto que al mismo tiempo planteaba soluciones híbridas a medio camino entre la regulación anterior y la supresión total ${ }^{33}$.

Respecto a la reforma realizada a través de la LO 3/1995, se ha pasado de contar con una de las legislaciones más avanzadas en torno a la votación de

30 BOCG-B, CD, 22 de octubre de 2010, n. ${ }^{\circ} 283-1$.

31 Es preciso recordar cómo el TC, a la hora de abordar el derecho de sufragio activo y pasivo, derivados del art. $23 \mathrm{CE}$, ha asegurado en alguna de sus sentencias: «el derecho de sufragio activo y el pasivo son aspectos indisociables de una misma institución, nervio y sustento de la democracia: el sufragio universal, libre, igual, directo y secreto» (STC 24/1990, FJ 2); añadiendo que son «dos derechos que encarnan la participación política de los ciudadanos en el sistema democrático, en conexión con los principios de soberanía del pueblo y de pluralismo político consagrados en el art. 1 CE» (SSTC 71/1989, FJ 3; y 119/1995, FJ 2), lo que "permite concluir que tales derechos se circunscriben al ámbito de la legitimación democrática directa del Estado y de las distintas entidades territoriales que lo integran» (SSTC 119/1985, FJ 3; y 153/2003, FJ 8).

32 BOCG-D, Congreso de los Diputados, n. ${ }^{\circ} 438,4$ de agosto de 2010, p. 10.

33 El informe del Consejo de Estado sobre la reforma electoral. Texto del informe y debates académicos, CEPC, 2009, pp. 92 y ss. 
nacionales residentes en el extranjero ${ }^{34}$, a otra con importantes restricciones para el ejercicio del derecho al voto. Entre otros aspectos novedosos, la reforma de 1995 contemplaba: la revisión continua y actualización mensual del censo electoral de modo que estuviera permanentemente actualizado ${ }^{35}$, la inscripción censal obligatoria, y la tramitación de oficio por las oficinas y secciones consulares. La premura de la entrada en vigor del cambio legislativo, hizo imposible el cambio de sistema de actualización censal, obligando a hacer un vuelco de los datos contenidos en los Registros de Matrícula consulares en el CERA de cada consulado, de origen decimonónico y cuya última regulación es por RD 3425/2000, de 15 de diciembre ${ }^{36}$. El Registro de Matrícula consular se compone, a su vez, de dos categorías de españoles: residentes y no residentes, siendo la primera categoría coincidente con el padrón de españoles residentes en el extranjero (PERE), del que se obtiene el CERA, que está formado por los inscritos en el PERE mayores de edad. No obstante, la realidad demostró deficiencias en la composición del CERA con los datos de los Registros de Matrícula consulares, lo que obligó a la Oficina del Censo Electoral a realizar una serie de recomendaciones para su depuración, tales como: contrastar datos de defunciones del INE para detectar fallecidos que seguían inscritos en el CERA, comunicación directa de la información a los propios electores, remisión de información para la comprobación por los consulados de la pervivencia de los inscritos con mayor edad, y el estudio de las devoluciones de la documentación electoral en elecciones precedentes ${ }^{37}$.

No obstante y a modo de inciso, para abordar el voto de los españoles residentes en el extranjero también es necesario hacer referencia a la Ley 40/2006, de 14 de diciembre, del Estatuto de la ciudadanía española en el exterior, y a la Ley $52 / 2007$, conocida como la Ley de Memoria Histórica. La entrada en vigor de la Ley de Memoria Histórica permitió — como reconocimiento singularizadoacceder a la nacionalidad española a los voluntarios de las Brigadas Internacionales sin renunciar a su anterior nacionalidad —art. 18-, así como a los hijos de padre o madre originariamente españoles y a los nietos de españoles exiliados y que tuvieron que renunciar a su nacionalidad. El plazo para adquirir la nacionalidad por consanguinidad en primer grado con ascendientes originariamente españoles o por ascendientes en segundo grado de consanguinidad exiliados,

34 Ripollés Serrano, M.R., op. cit., p. 207.

35 RD 157/1996, por el que se dispone la actualización mensual del censo electoral y se regulan los datos necesarios para la inscripción en el mismo.

36 La función de los Registros de Matrícula, como el propio R.D. 3425/2000 determina es: «ser instrumento eficacísimo en nuestras Misiones Diplomáticas y Oficinas Consulares para extender la protección diplomática y consular de España a todos los españoles que se encuentren viviendo en el extranjero, bien sea como residentes permanentes, bien en una estancia provisional o temporal, pues, cuando se desata una catástrofe natural o un conflicto bélico o, simplemente, se produce un accidente o una situación personal digna de protección, todos los españoles tienen el mismo derecho a ser protegidos por nuestros agentes diplomáticos o consulares».

37 Ripollés Serrano, M.R, op. cit., p. 208. 
finalizó a los cuatro años de la entrada en vigor de la Ley. Pese al gran número de solicitudes, en 2014 se registró una PNL del Grupo parlamentario Socialista que, entre otras cuestiones, instaba al Gobierno a articular medidas para facilitar el acceso a la nacionalidad por esta vía a más personas, cuestión también reflejada en una Proposición de Ley del Grupo parlamentario Unidos Podemos-En Comú Podem-En Marea del año 2017.

Así mismo, la Ley 36/2002, de modificación del Código Civil en materia de nacionalidad, trajo consigo un incremento sustancial de españoles inscritos en el CERA, al reconocer: el derecho de adquisición de la nacionalidad española a los hijos de padre o madre originariamente español y nacido en España, a quien haya estado o esté sujeto a patria potestad de un español, y la posibilidad de recuperar la nacionalidad, sin ser residente legal en España, para los emigrantes e hijos de emigrantes. De estos cambios legislativos y para tomar conciencia del impacto real, entre 2013 y 2016 —únicos publicados por el INE—, más de medio millón de personas adquirieron la nacionalidad por algún motivo, lo que da cuenta del gran número de personas que se han incorporado como nacionales, muchos de ellos sin residir en España. Por último, también se explica el mayor número de españoles en el extranjero como consecuencia de la emigración debida a factores de naturaleza económica — la crisis desde 2009 ha expulsado a miles de españoles en busca de oportunidades fuera del territorio nacional-.

El procedimiento de voto de los españoles residentes en el extranjero inscritos en el CERA tras la reforma electoral de 2011:

La reforma operada por la LO 2/2011 introducía la opción para los españoles residentes en el extranjero del voto en urna durante los tres últimos días de campaña, además del voto por correspondencia, lo que a juicio del legislador permitía incrementar las garantías en el ejercicio del derecho al sufragio activo. Es decir, desde 2011, los españoles inscritos en el CERA pueden optar por ejercer su derecho al voto a través de dos procedimientos distintos: el voto por correo o el voto en urna en la embajada o consulado correspondiente a su lugar de residencia en el extranjero.

Pero, sin lugar a dudas, la introducción del voto rogado ha sido una de las cuestiones más denostadas desde su implantación. El nuevo art. 75 LOREG establece, en su primer apartado, que los españoles residentes-ausentes deben formular mediante impreso oficial la solicitud de voto dirigida a la Delegación Provincial de la Oficina del Censo Electoral antes del vigésimo quinto día posterior a la convocatoria ${ }^{38}$; solicitud que debe hacerse en cada convocatoria electoral, sin que tenga carácter permanente en el tiempo. Recibida esta solicitud, las diferentes Delegaciones Provinciales de la Oficina del Censo Electoral remiten a la dirección facilitada por el elector la documentación electoral —el sobre o los

38 La previa inscripción en el censo electoral para los residentes en el extranjero también es obligatoria, por ejemplo, en países como Portugal o Francia. 
sobres y las papeletas-, dos certificados para atestiguar la inscripción en el CERA y un sobre donde debe figurar la dirección de la Junta Electoral competente, y otro con la dirección de la Oficina Consular de Carrera o Sección Consular de la Misión Diplomática en la que estén inscritos (art. 75.2 LOREG). El art. 75.3 LOREG establece que el envío de los sobres se realizará por correo certificado y antes del trigésimo cuarto día posterior a la convocatoria electoral si no ha habido impugnación de las candidaturas y antes del cuadragésimo segundo de haberse producido tal impugnación.

En este momento, los electores pueden optar por una de las dos modalidades para ejercer el derecho al voto: voto por correo o en urna. Si se opta por el voto por correo, deben incluir en el sobre dirigido a la correspondiente Junta Electoral los sobres de votación, el certificado de inscripción en el censo, fotocopia del pasaporte o DNI o certificación de nacionalidad o de inscripción en el Registro de Matrícula Consular, y enviarlo en el sobre dirigido a la Oficina Consular de Carrera o Sección Consular de la Misión Diplomática a la que el elector esté adscrito, por correo certificado no más tarde del quinto día anterior al día de la elección (art. 75.4 LOREG). Como hemos indicado, también pueden optar por el voto en urna en los tres últimos días de campaña (entre el cuarto y segundo día, ambos inclusive, antes del día de la votación) y lo podrán hacer mediante la entrega personal de los sobres en las oficinas o secciones consulares donde estén inscritos o los lugares habilitados para ello (art. 75.5 LOREG). Para el voto en urna, el elector debe acreditar su identidad ante el funcionario consular mediante pasaporte, DNI, certificación de nacionalidad o de inscripción en el Registro de Matrícula Consular, así como entregar uno de los certificados de inscripción en el censo de residentes ausentes recibido, tras lo que el elector depositará el sobre dirigido a la Junta Electoral correspondiente para su escrutinio, siendo el funcionario consular el encargado de estampar el sello de la oficina consular en el sobre para hacer constar la fecha del depósito del voto (art. 75.6 LOREG). Al extenderse la votación durante varias jornadas, deberán tomarse las medidas oportunas para garantizar la guarda y custodia de las urnas - con su precinto al finalizar cada una de las jornadas de votación-, así como facilitar la presencia de los representantes de las candidaturas en las dependencias consulares habilitadas para el depósito del voto en urna (art. 75.7 LOREG).

Transcurrido el plazo del depósito del voto en urna, el funcionario consular expedirá un acta que contendrá el número de certificaciones censales recibidas - y las incidencias que hubieran podido producirse—, así como el número de sobres recibidos por correo hasta la finalización del plazo de depósito del voto en urna. Al día siguiente, los sobres depositados por los electores y los recibidos por correo junto al acta expedida por el funcionario consular deberán ser remitidos, mediante envío electoral, a la Oficina constituida al efecto en el Ministerio de Asuntos Exteriores, que procederá al envío urgente de estos sobres a las Juntas Electorales correspondientes (art. 75.8 LOREG). Para la validez de los votos, deberá acreditarse el cumplimiento de los plazos mediante los sellos o 
inscripciones de las secciones consulares y oficinas de correos correspondientes (art. 75.9 LOREG). Son múltiples los fallos detectados en los envíos, más allá de los retrasos producidos, por lo que parece oportuno que el Gobierno desarrolle y complemente aspectos procedimentales para dotar de seguridad jurídica a todo el proceso de emisión de votos, «especialmente aquellos que tengan que ver con la pureza y verdad del sufragio» ${ }^{39}$.

Por último, la fase del escrutinio de los votos de los españoles inscritos en el CERA, de la que se encargan los apartados 10 y 11 del art. 75 LOREG: el día del escrutinio general, y antes de proceder al mismo, la Junta Electoral competente se constituye en Mesa Electoral, a las ocho horas de la mañana, con los Interventores que a tal efecto designen las candidaturas concurrentes. A continuación, su Presidente procede a introducir en la urna o urnas los sobres de votación de los residentes ausentes recibidos hasta ese día y el Secretario anota los nombres de los votantes en la correspondiente lista. Acto seguido, la Junta escruta todos estos votos e incorpora los resultados al escrutinio general.

Mención aparte merece el caso de los electores inscritos en el CERA que, eventualmente, se encuentren en España durante el periodo electoral, a quienes se permite el voto por correspondencia pero, en ningún caso, el voto presencial en Mesa electoral. Es, en nuestra opinión, lógico que se permita en estas situaciones el mecanismo ordinario del voto por correo y no el presencial (art. 73.1 LOREG; también resulta de interés, por todas, la STC 169/1991) porque, en caso de permitirse, un español residente-ausente podría votar hasta en dos ocasiones, si tenemos en cuenta que el escrutinio de los votos del CERA se realiza en día posterior y distinto al de los votos del CER, de tal forma que podría darse la casuística de un español residente-ausente que hubiera emitido su voto en el extranjero -en las oficinas o secciones consulares o lugares habilitados al efecto, pueden hacerlo hasta dos días antes del día de celebración de las elecciones- y, por circunstancias, el día de la votación se encontrase en España para emitir también su voto de forma presencial. En todo caso, de haber duplicidad de voto, el ordinario y el emitido desde el extranjero, será válido el primero y nulo el segundo.

Como hemos podido comprobar, el procedimiento para ejercer el derecho al voto por los españoles residentes en el extranjero es largo y comienza con la solicitud del voto - voto rogado - como primera dificultad, a las que se suman la distancia hasta la embajada o el consulado, los retrasos en la recepción y envío de documentación, etc. Sin lugar a dudas, el procedimiento establecido es una verdadera carrera de obstáculos que provoca el desánimo inicial y, en última instancia, un sentimiento de frustración porque aun completando todo el proceso de solicitudes y envíos, la documentación con el voto puede no llegar a tiempo para

39 García Maнamut, R., «La reforma electoral (LO 2/2011) y el voto de los españoles en el exterior (CERA). La inefectividad del derecho de sufragio de los españoles en el exterior. Una necesaria revisión», TRC, n. ${ }^{\circ} 30,2012$, p. 274. 
su escrutinio. Ante esta realidad, el legislador incluyó en el último apartado del artículo 75 de la LOREG la posibilidad de que el Gobierno, previo informe de la JEC, pudiera «regular los criterios y limitar los supuestos de aplicación de este artículo, así como establecer otros procedimientos para el voto de los residentes ausentes que vivan en Estados extranjeros donde no es practicable lo dispuesto en este artículo» pero, a grandes rasgos, como comprobaremos en este trabajo, las medidas han sido escasas y los efectos del procedimiento, nefastos para la participación electoral.

\section{LA INCIDENCIA EN LA PARTICIPACIÓN DE LOS ESPAÑOLES RESIDENTES-AUSENTES TRAS LA REFORMA}

Hay pocas cuestiones que generen menos dudas que la tozudez de los datos expresados en cifras numéricas y, en esta ocasión, no es diferente. Para ver en qué medida el nuevo procedimiento de voto ha incidido sobre los datos de participación de los españoles residentes-ausente, compararemos la participación en elecciones equivalentes antes y después de la entrada en vigor de la reforma de 2011. En las Elecciones a Cortes Generales de 2004, los inscritos en el CERA eran 1.009.209, de los que 304.629 votos llegaron por correo a las Juntas Electorales Provinciales (JEP), esto es, el 30'17\% del total; en las Elecciones a Cortes Generales de 2008, los inscritos en el CERA eran 1.205.132, de los que 384.154 se recibieron por correo en las JEP, el 31'88\% del total. En las Elecciones a Cortes Generales de 2011, el número de inscritos en el CERA ascendía a 1.482 .750 y de ellos, se presentaron 164.943 solicitudes de voto, siendo aceptadas 138.037 y 73.359 votos fueron entregados en las JEP; es decir, el 11'12\% de los electores con derecho al sufragio activo solicitaron el voto, el $84 \%$ fueron aceptadas, pero sólo el 53'14\% de las solicitudes aceptadas llegaron a las JEP y apenas el 4'95\% del total de electores inscritos en el CERA participaron de forma efectiva. En las Elecciones a Cortes Generales de 2015, el número de inscritos en el CERA ascendía a 1.880.026 (el 5'15\% del total de electores resultante de sumar CER y CERA), se presentaron 161.228 solicitudes, aceptándose 151.061 el 94\% de las presentadas- y entregándose en las JEP 88.899 votos —el 58'85\% de las solicitudes aceptadas-, con un porcentaje real de participación del $473 \%$ de los inscritos en el CERA. Por último, en este tipo de elecciones, en las celebradas a Cortes Generales en 2016, el número de inscritos en el CERA fue de 1.924.012, se presentaron 175.551 solicitudes de voto, siendo 169.658 aceptadas —el 97\% de las presentadas-, y 121.277 votos fueron entregados en las Juntas Electorales Provinciales - 71'48\% de las solicitudes aceptadas-, lo que representa el 6.30\% del total de inscritos en el CERA.

Veamos ahora la participación de los españoles residentes ausentes durante el mismo periodo en las elecciones municipales y hasta 2011, primer año en que fueron excluidos como electores tras la entrada en vigor de la reforma. En las 
elecciones de 2003, había 1.063.876 inscritos en el CERA, presentándose 122.295 solicitudes de voto por correo de las que se aceptaron 97.785 - el 79 '96\% - y 47.718 fueron entregados en las mesas electorales, dejando la participación en el 4’49\%; 5.294 votos fueron depositados en las oficinas consulares. En los comicios locales de 2007, se presentaron 128.483 solicitudes para votar por correo - 103.862 aceptadas, de las que 67.235 se entregaron en las mesas electorales, el $6473 \%$ sobre las aceptadas-, con 5.367 votos depositados en las oficinas consulares; de un CERA con 1.168.638 nacionales, la participación fue del $5{ }^{\prime} 75 \%$. La baja participación de los españoles residentes en el extranjero en las elecciones municipales como tónica habitual, tiene una explicación práctica bastante lógica bajo nuestro punto de vista —además de por la obligación de rogar el voto con anterioridad a 2011 - , relacionada principalmente en torno a dos razones a su vez relacionadas entre sí: la práctica partidista en este tipo de elecciones suele concentrarse más en los vecinos del propio municipio, y la pérdida de relación y vínculo de los residentes en el extranjero con la vida del municipio. En primer término, en efecto, la práctica partidista en las elecciones locales se dirige al electorado más próximo, con un tipo de campañas electorales centradas en propuestas con los vecinos residentes en el propio municipio como destinatarios, sobre todo porque la cercanía de la administración local invita a este tipo de planteamientos por los partidos políticos, que no muestran excesivo interés por captar los sufragios de quienes viven lejos del municipio. Y, por otro lado, relacionado con lo anterior, los españoles que residen en el extranjero, lejos del municipio de origen, pierden interés por la política local, basada decisiones en torno a servicios públicos que sólo afectan a los vecinos residentes en el mismo municipios; por lo que esta falta de conexión entre las decisiones del ámbito local y la vida de los españoles en el extranjero es lo que en buena medida explica también su baja participación en las elecciones.

Y, por último, la participación en los últimos cuatro comicios autonómicos. En 2003, se entregaron en las JEP 100.930 votos, que representaban el 20'31\% de los electores inscritos en el CERA. En 2007, 130.510 votos que representaban el 23'57\% del total de electores residentes ausentes. En 2011, 705.781 figuraban como inscritos en el CERA, 69.234 presentaron solicitud de voto — se aceptaron 58.097 , el $83^{\prime} 91 \%$ - y 26.030 fueron entregados en las JEP, arrojando un dato de participación del 3’69\%. Y, en las recientes elecciones autonómicas de 2015, 919.082 españoles figuraban como inscritos en el CERA para este tipo de elecciones, de los que 50.256 presentaron solicitud de voto, siendo el $93 \%$ de ellas aceptadas —en concreto, 46.543-y fueron entregadas en las JEP el $58{ }^{\prime} 73 \%$ de las aceptadas —en términos absolutos: 27.336—, obteniendo como resultado de participación del 2'97\%.

Tras revisar los datos públicos de los principales procesos electorales, desde la entrada en vigor de la reforma de 2011 y hasta la fecha, la introducción del voto rogado ha supuesto un verdadero obstáculo para el ejercicio del derecho al voto vulnerando, a nuestro juicio, la previsión del artículo 68.5 CE en conexión con el 
contenido de los artículos 1.2, 9.2, 23 y 42 CE. Así, y como hemos podido comprobar, las cifras de participación electoral han disminuido en hasta seis veces menos de las registradas con anterioridad a la reforma de 2011 en los procesos electorales equivalentes, lo que demuestra que el voto rogado es un límite para el efectivo ejercicio del derecho a la participación política a través del sufragio activo.

\section{LA CONTRARREFORMA COMO ÚNICA OPCIÓN PARA PALIAR LOS EFECTOS PERJUDICIALES DEL VOTO ROGADO EN EL EXTERIOR}

Las consecuencias del voto rogado, con cotas de participación electoral de los residentes-ausentes, como hemos comprobado muy por debajo de lo previsible, ha provocado que uno de los partidos proponentes de la modificación legislativa vigente desde 2011 planteara, apenas transcurrido poco más de año y medio desde su entrada en vigor, suprimir la modalidad del voto rogado ${ }^{40}$ y reinstaurar el envío de oficio de la documentación electoral. De hecho, de los dos principales partidos políticos que respaldaron la reforma electoral, PSOE y PP, tan sólo el PP defiende hoy en día en buena medida la decisión adoptada por amplia mayoría parlamentaria en el momento de su aprobación; el PSOE, en cambio, ha virado en su posición política sobre esta reforma, dando un giro de ciento ochenta grados. La «mala prensa» asociada, en particular, a estos dos partidos políticos por los efectos sobre la participación de la puesta en marcha del voto rogado, es con toda probabilidad el motivo de explicación del viraje político. Incluso, y debido a la baja participación efectiva en los comicios de los últimos años, tras la entrada en vigor de la reforma de la LOREG, se ha llegado a registrar la propuesta de crear una Comisión de Investigación sobre el procedimiento del voto desde el extranjero.

El voto de los españoles en el extranjero se ha convertido en una de las cuestiones principales objeto de la Subcomisión para la reforma electoral, creada en el seno de la Comisión Constitucional en la presente XII legislatura ${ }^{41}$, y cuyos trabajos siguen hoy en día tras sucesivas prórrogas ${ }^{42}$. Para intentar sintetizar los trabajos de la Subcomisión, parece oportuno destacar, de entre todas las comparecencias celebradas, tres de ellas: la del Presidente de la JEC, la de la Directora General de Españoles en el Exterior y de Asuntos Consulares y Migratorios del Ministerio de

40 Proposición de LO de reforma de la LOREG para facilitar el ejercicio del voto de los españoles en el exterior, del GPPSOE, BOCG-B, n. ${ }^{\circ}$ 96-1, de 25 de octubre de 2012. Reiterada en BOCG-B, n. ${ }^{\circ}$ 10-1, de 10 de febrero de 2016, y BOCG-B, n. ${ }^{\circ} 13-1$, de 9 de septiembre de 2016.

41 BOCG-D, CD, n. ${ }^{\circ} 137$, de 5 de abril de 2017, p. 12.

42 BOCG-D, CD, n. ${ }^{\circ} 271$, de 20 de diciembre de 2017, p. 3; y BOCG-D, CD, n. ${ }^{\circ} 410$, de 13 de septiembre de 2018, p. 38. 
Asuntos Exteriores y de Cooperación, y la de los representantes de la «Marea Granate»; en las que se mencionaron los problemas de procedimiento detectados, así como posibles soluciones para paliar los efectos del voto rogado.

Comparecencias ante la Subcomisión para la reforma electoral:

La primera de las comparecencias que pretendemos sintetizar y destacar su contenido en este trabajo es la del Presidente de la JEC de octubre de $2017^{43}$, que atribuye los problemas del voto rogado manifestados en la baja participación desde su generalización, a tres razones fundamentalmente: primero, por la obligación impuesta al elector a tomar la iniciativa de comunicar su propósito de votar; segundo, por el retraso en la recepción por los electores de la documentación remitida por la Delegación Provincial de la Oficina del Censo Electoral y por las oficinas consulares de los sobres que les remiten los electores —retraso que se debe, en la mayor parte de los casos, al funcionamiento de los servicios postales del país extranjero- - así como defectos en el funcionamiento de las oficinas consulares, singularmente por las limitaciones de medios para organizar los horarios del depósito de los sobres electorales en las urnas y organizar la posterior remisión a las juntas electorales provinciales de los votos recibidos; y tercero, por el escaso tiempo en que han de realizarse todas las operaciones necesarias para que el voto emitido fuera de España llegue a ser escrutado. En torno a los problemas detectados por el Presidente de la JEC, aporta algunas soluciones ${ }^{44}$, aunque destacaremos de forma especial la referencia al sistema de voto telemático.

Así, el Presidente de la JEC recuerda la propuesta de la JEC en su informe de 16 de noviembre de 2016 (Acuerdo JEC n. ${ }^{\circ}$ 261/2016), para establecer un sistema de voto telemático para los electores inscritos en el CERA y los del ERTA. Según su criterio, ésta sería la solución menos costosa y más eficaz, al ofrecer la tecnología en la actualidad instrumentos idóneos para comprobar la identidad de quienes intervienen en las comunicaciones producidas por medios electrónicos y

43 DSCD, n. ${ }^{\circ} 342$, de 18 de octubre de 2017, pp. 2-17.

44 En primer lugar, apuesta por dotar de una mayor eficiencia al voto CERA sin menoscabar gravemente las garantías de pureza del mismo, remitiéndose al informe de la JEC de noviembre de 2016, donde señala que debe considerarse la posibilidad de que la Administración consular se ponga en contacto con los electores CERA inscritos en su registro de matrícula y con los residentes temporales que se hayan inscrito con tal condición para facilitarles, respecto de cada proceso electoral, la información pertinente. Para ello, debía establecerse un procedimiento adecuado, a fin de que los consulados, nada más producirse una convocatoria electoral, comunicaran electrónicamente a los españoles inscritos en su registro la posibilidad de servirse de él - del consulado - y recibir la documentación necesaria. En segundo lugar, apuesta por dotar a las oficinas consulares de medios personales y materiales suficientes para desempeñar adecuadamente sus tareas electorales. De hecho, y manteniendo la modalidad del voto rogado, propone arbitrar una solución parecida a contemplada por el art. 190 LOREG para el voto en las elecciones locales antes de 2011. En tercer lugar y último lugar, plantea medidas en sistema de plazos, reconociendo la dificultad del encaje de cualquier modificación en este sentido porque la ampliación del plazo íntegro que debe durar el proceso electoral — cincuenta y cuatro días - conllevaría una prolongación del tiempo de interinidad en que se encuentran muchas de las instituciones públicas; y, además, esta modificación del plazo, así como el cambio del día de realización del escrutinio general, habría de respetar lo contenido en el art. 68.6 CE, que establece la fecha de las elecciones tendrán lugar entre los treinta y los sesenta días de la terminación del mandato de los diputados. 
para garantizar el secreto de aquellos contenidos de la misma que lo requieran. Así mismo, posibilita que la Administración exterior ponga a disposición de los electores CERA y ERTA terminales desde las que efectuar las comunicaciones precisas con la Oficina del Censo Electoral y con las juntas electorales. Y respecto a esta cuestión, apunta a que la introducción de un sistema de voto telemático vía internet sería excepcional, siendo consciente que no es totalmente equiparable a la emisión presencial del voto porque no ofrece, en modo alguno, las mismas garantías de visibilidad, transparencia e implicación individual.

Por otro lado, la Directora General de Españoles en el Exterior y de Asuntos Consulares y Migratorios del Ministerio de Asuntos Exteriores y de Cooperación ${ }^{45}$, señaló que la institución a la que representa es la encargada de coordinar y supervisar las oficinas consulares, englobando la gestión del Registro de Matrícula Consular, la coordinación del CERA y la participación en las elecciones de los españoles en el exterior; y explicó el protocolo seguido en cada proceso electoral. También se refirió a la forma en que se establece comunicación con los españoles residentes en el extranjero, manifestando que «cada vez más frecuentemente las oficinas consulares se dirigen mediante correo electrónico a los electores para informarles de las cuestiones sobre la información electoral», aunque no existe obligación por parte de los inscritos en el padrón de españoles residentes en el extranjero (PERE) de facilitar su correo electrónico o teléfono móvil ni tampoco existen medios técnicos para realizar envíos masivos, lo que sin duda dificulta enormemente la labor informativa para hacer llegar todos los datos relativos a las elecciones y el ejercicio del derecho del sufragio desde el extranjero.

Además, destacó algunas de las dificultades que, a su juicio, existen para garantizar el ejercicio del voto de los españoles residentes en el extranjero. La primera dificultad estriba en que algunos ciudadanos españoles no están inscritos en el censo, pese a la obligación de los españoles que residen habitualmente en el extranjero de inscribirse en el Registro de Matrícula Consular. El hecho de no estar inscrito en el Registro de Matrícula Consular en el momento de la convocatoria electoral impide formar parte del censo y, por tanto, no pueden participar en las elecciones. Por otro lado, para el caso de los no residentes, la inscripción no es obligatoria, pero sí preceptiva para participar en los procesos electorales desde el extranjero (art. 2.2 del RD 1621/2007). Por tanto, la inscripción en el Registro de Matrícula Consular es conditio sine qua non para poder ejercer el derecho al voto por los españoles en el extranjero. Tras la inscripción en el Registro de Matrícula como españoles no residentes, la solicitud de voto debe ser realizada en la Oficina Consular de Carrera o Sección Consular de la Embajada personalmente y de forma presencial (art. 3.3 del RD 1621/2007), lo que dificulta el ejercicio del derecho de voto porque pueden darse casos en los que un español se encuentre a centenares o miles de kilómetros de la oficina o sección consular más cercana. El

45 DSCD, n. ${ }^{\circ} 403$, de 13 de diciembre de 2017, pp. 2-12. 
voto de los españoles temporalmente en el extranjero — voto ERTA — se realiza por correo y con destino a España; estos electores, ausentes del territorio nacional temporalmente, figuran inscritos en el Censo de Electores Residentes (CER) y no en el CERA. En el caso de los votantes integrados en el CERA, la legislación electoral permite ejercer el derecho al voto en dos modalidades: voto por correspondencia o voto presencial en la oficina consular ${ }^{46}$.

Pero, sin duda, las mayores dificultades del voto por correo en el extranjero identificadas por la Directora General, tanto en los envíos a las oficinas consulares para el voto CERA como los dirigidos a España con el voto ERTA, dependen de dos cuestiones: de la existencia de convenio con el país de procedencia para la gratuidad del envío y de la eficacia de sus servicios postales. Sobre la primera cuestión, a día de hoy España mantiene convenio con los servicios postales de 16 países donde se concentra el $75 \%$ de los españoles en el extranjero, pero no con algunos de nuestro entorno más inmediato como, por ejemplo, Italia. Y, en cuanto a la eficacia de los servicios postales, es posible encontrar países sin un servicio de correo postal formalizado, otros países donde las huelgas son frecuentes y en otros la saturación es tal que no absorben la carga de trabajo extra de los envíos electorales; lo que provoca que haya situaciones en las que los electores reciben con retraso la documentación o ni siquiera la reciben, y lo mismo sucede cuando el elector envía su voto y no es recibido a tiempo en las oficinas consulares o en España.

Por último, destacamos el contenido de la comparecencia de la portavoz del colectivo «Marea Granate» ${ }^{47}$, que se basó en un informe de propuestas para la reforma de la LOREG sobre algunos aspectos relevantes que merecen mención: derogación del voto rogado, ampliación de los plazos de los envíos electorales, la dotación de medios a los consulados y a la Administración en el exterior en general, y la reforma del sistema de voto dotando de mayor transparencia al proceso electoral en el exterior. Para el colectivo, hay una relación causa-efecto indudable de la introducción del voto rogado y la baja participación porque, a su vez, traslada obligaciones de la Administración al ciudadano en cuanto a la depuración del censo; pero además, a su juicio, el principal problema para que los votos lleguen desde el extranjero no es tanto el funcionamiento de los servicios postales de los países, sino la brevedad de los plazos — quince días en el caso de una situación normal y siete si hay impugnación de candidaturas-.

Así mismo, ponen de manifiesto las enormes dificultades para las inscripciones consulares, existiendo un desfase entre inscritos y residentes reales en el extranjero, por lo que proponen la elaboración de un protocolo de actualización del censo que permita la informatización de los procesos de inscripción, y crear

46 García Mahamut, R., op. cit., p. 275, ha calificado al voto presencial en las embajadas y en las oficinas consulares como una «ficción jurídica», puesto que los votos se acaban finalmente remitiendo por correo a las Juntas Electorales Provinciales en España.

47 DSCD, n. ${ }^{\circ} 403$, de 13 de diciembre de 2017, pp. 26-36. 
una sede electrónica para los trámites de inscripción, modificación de domicilio o subsanación de censo. Por otro lado, se propone un sistema de voto múltiple: por correo, presencial y por delegación de poder — esta última modalidad, basada en las experiencias de países como Francia, Reino Unido o Bélgica-. Y, de manera central, consideran que la modificación de los plazos es conditio sine qua non para la mejora del derecho al voto desde el exterior, además de la derogación del ruego del voto, proponiendo un adelanto de la convocatoria electoral, la ampliación del tiempo de subsanaciones de las inscripciones en el censo, la ampliación de los tiempos de envíos desde las oficinas del censo electoral de la documentación al elector y la ampliación de plazos de escrutinio, así como habilitar la posibilidad de descargar el material de votación por el elector en caso de que no haya sido recibido. Muestran, además, su oposición total a la incorporación del voto electrónico como posible solución a los problemas para el ejercicio del derecho al voto desde el exterior, y para sostener el fracaso de este medio de votación aluden a casos en los que se ha dado marcha atrás en su uso - Francia, Holanda o México - y a la vulneración de principios básicos asociados al proceso electoral, tales como posibilitar la auditoría de los resultados o la universalidad, igualdad, libertad y secreto del voto. Por último, destacan la necesidad de incorporar mejoras en las garantías del proceso electoral en el exterior: incremento de canales para transmitir la información, aumento de la transparencia y la seguridad, garantizar la gratuidad del voto, adecuar los recursos humanos y técnicos al incremento de la emigración, y solicitando la creación de una circunscripción exterior para reforzar su vinculación con la política nacional.

El papel de la JEC ha sido clave, tanto para el inicio de la reforma con el informe de 2009 que, junto con el del Consejo de Estado, sirvió de base como, en determinadas ocasiones, para intentar paliar a través de instrucciones y acuerdos - de los que haremos mención a algunos de ellos, a modo de muestra- los efectos negativos que en la práctica producía el nuevo marco legislativo, siempre dentro del margen que el mismo permitía, así como para conocer de los recursos que se le planteaban al respecto. Tanto es así que, incluso, llegó a conocer de un recurso contra la convocatoria de las elecciones generales de diciembre de 2015 por violación del derecho fundamental del voto de los residentes-ausentes, basándose en las trabas burocráticas generadas por el voto rogado, que fue inadmitido por la JEC.

De hecho, la propia JEC, en las primeras elecciones de vigencia de la reforma de 2011, y a la vista de las restricciones que de por sí planteaba el voto rogado para el ejercicio del derecho de sufragio activo, hizo una interpretación flexible en torno a las condiciones de la solicitud, permitiendo solicitudes presentadas por fax y las solicitudes por correo de varias personas en un mismo sobre, siempre que éstas estuvieran vinculadas entre sí por lazos familiares o similares (Acuerdo JEC n. ${ }^{\circ}$ 583/2011). Además, la JEC emitió una circular para la resolución de posibles dudas en relación con el voto en urna en las Oficinas Consulares de España (Acuerdo JEC n. ${ }^{\circ}$ 685/2011), destacando los siguientes aspectos sobre el funcionamiento de 
las Oficinas Consulares en la semana previa a las elecciones: establecimiento de un horario especial — de mañana y tarde — con posibilidad de acudir después de la jornada laboral ordinaria del país, derecho de presencia durante toda la jornada de los representantes de las candidaturas, presencia de al menos un funcionario en cada misión consular para la resolución de cuestiones que pudieran surgir durante la jornada, y sellado y precinto de las urnas al final de cada jornada de depósito de los votos.

Respecto a la insuficiencia de los plazos establecidos para emitir el voto desde el extranjero, también se pronunció nítidamente de la siguiente manera: «Las principales dificultades para la efectividad de la recepción en tiempo hábil del voto de los electores inscritos en el CERA y de los electores residentes temporalmente en el extranjero reside en la insuficiencia de los plazos establecidos en la LOREG, particularmente en los casos en los que se presentan recursos contra los acuerdos de proclamación de candidaturas, así como en los problemas derivados del funcionamiento de los servicios postales de otros Estados, circunstancias ajenas a las competencias de la JEC» (Acuerdo JEC n. ${ }^{\circ}$ 167/2015). Porque, además, en el caso de estar pendiente la resolución de recurso de amparo por el TC respecto la proclamación de candidaturas, el envío de la documentación electoral se realiza una vez que se haya producido la resolución del recurso de amparo por el TC (Acuerdo JEC n. ${ }^{\circ}$ 154/2012).

Pero, sobre todo, ante las deficiencias y problemas detectados en las diferentes elecciones celebradas desde 2011, la JEC elaboró un informe (261/2016) al que hemos hecho referencia en varias ocasiones, de 16 de noviembre de 2016, donde constató «notables disfunciones en el sistema establecido por el legislador que agudizan su falta de efectividad, ya manifestada en las primeras elecciones generales en que se aplicó, las de 2011». Además, la JEC identificó las principales causas que pueden explicar esta realidad ${ }^{48}$. Sin olvidar, además, que todo el procedimiento depende, a su vez, del buen o mal funcionamiento de los servicios postales extranjeros. Estos retrasos, añade la JEC, se podrían mitigar con la recepción del elector de la documentación de votación por vía telemática o a través de una papeleta en blanco donde se manifieste el sentido del voto a una candidatura, como ocurría para las elecciones locales antes de la supresión del artículo 190 de la LOREG.

48 «(i) la disposición del elector a tomar la iniciativa de comunicar su propósito de votar, de muy difícil valoración, (ii) el retraso en la recepción por los electores de la documentación remitida por la Delegación Provincial de la Oficina del Censo Electoral; (iii) el retraso con que las oficinas consulares reciben los sobres que les remiten los electores; (iv) las limitaciones de dichas oficinas para organizar los horarios de depósito de los sobres electorales en las urnas; (v) algunos defectos en el funcionamiento de las oficinas consulares; (vi) la necesaria remisión desde la Oficina del Ministerio de Asuntos Exteriores a las Juntas Electorales Provinciales de los sobres recibidos; y (vii) el escaso tiempo en que han de realizarse todas las operaciones necesarias para que el voto del elector que desee acogerse a este sistema llegue a ser escrutado». 
Así mismo, la JEC ha mostrado «preocupación por la precariedad de medios de que disponen las Oficinas Consulares para realizar las funciones electorales que les corresponden, que ha podido apreciar en este caso y en otros análogos, y requiere al Ministerio de Asuntos Exteriores y de Cooperación para que adopte las medidas personales y materiales que resulten necesarias para hacer frente a esta situación y evitar que puedan producirse situaciones como la ocurrida en el presente asunto» (Acuerdo JEC n. ${ }^{\circ}$ 59/2016). De igual modo, constata el estrecho margen temporal para realizar todos los trámites necesarios que garanticen la llegada de los votos a las correspondientes juntas electorales para su escrutinio. Por ello, plantea la posibilidad de que tanto la recepción y entrega de la documentación, así como la emisión del voto, se pueda realizar conforme a medios telemáticos. Incluso, plantea como propuesta la introducción del voto por internet para los electores residentes en el exterior, como ya hiciera en 2009 el Consejo de Estado.

En torno a la opción de introducir el voto por internet para facilitar el derecho de sufragio activo de los españoles residentes en el extranjero, la JEC en el citado informe de 2016 hizo un recorrido por el marco legislativo tanto nacional como internacional que lo posibilitaría, así como mencionar ejemplos de países con experiencias en voto a través de internet - Noruega, Holanda, Francia, Estonia o Suiza- La JEC no ve obstáculo en la Constitución española actual para introducir la modalidad del voto por internet, siempre de forma excepcional y con una nueva previsión legal que lo incorporara. Del mismo modo, debe garantizarse en todo momento que el voto por internet sea universal, igual, libre, directo y secreto, ante lo cual existen algunas dudas notables que la propia JEC manifiesta en su informe.

Partimos de la siguiente premisa respecto a las modalidades de voto que establece el legislador: «la determinación de los instrumentos materiales de votación, es decir, de todos aquellos medios que ha de utilizar el elector a la hora de elaborar y expresar su opción política, es una de las decisiones más relevantes que ha de tomar el legislador a la hora de regular la organización de las elecciones» ${ }^{49}$ que, a día de hoy, se basa en el papel y donde los elementos principales son: papeletas, sobres, urnas y cabinas de votación. Cambiar los instrumentos materiales de votación eliminando las papeletas y los sobres con la introducción del voto electrónico presencial $^{50}$, no supondría ninguna mejora sustancial para los electores españoles residentes en el extranjero, salvo que fuera telemático ${ }^{51}$, esto es, a través de

49 GÁlvez Muñoz, L., «Aproximación al voto electrónico presencial: estado de la cuestión y recomendaciones para su implantación», TRC, n. ${ }^{\circ} 23,2009$, p. 259.

50 El legislador en el País Vasco ya introdujo esta posibilidad de voto electrónico en 1998, siendo de interés el trabajo de FERNÁNDEZ Riveira, R.M., «El voto electrónico: el caso vasco», REP (Nueva Época), n. ${ }^{\circ} 112,2011$, pp. 199-236.

51 Presno Linera, M.A., «Premisas para la introducción del voto electrónico en la legislación electoral española», REP, n. ${ }^{\circ} 173,2016$, pp. 287 y ss. 
internet. El voto por internet puede contribuir a facilitar el voto sin necesidad de desplazarse al colegio electoral, lo que podría traducirse en mayor participación, aunque también tiene muchos argumentos en contra de su implantación: se pierden garantías para comprobar que el voto corresponde efectivamente al elector, que lo hace en libertad sin coacciones y de forma secreta, así como la pérdida de control por los propios electores y los representantes de los partidos políticos del proceso electoral, rompiendo la liturgia de las elecciones y quedando al albur de la seguridad que ofrezcan las conexiones a distancia, no exentas de posibles ataques por parte de hackers o simples cibernautas delincuentes ${ }^{52}$. Respecto de la viabilidad de introducir el voto por internet para solventar los problemas en torno al ejercicio del derecho de sufragio activo por los españoles en el extranjero, no parece una solución viable desde un punto de vista de las garantías constitucionalmente exigibles respecto al voto — sufragio universal, igual, libre, directo y secreto; arts. 68.1 y $140 \mathrm{CE}$ - En este sentido, el sistema de voto por internet plantea dudas razonables en torno a, al menos, las siguientes cuestiones: seguridad y transparencia en el procedimiento de votación, la relevancia del elemento técnico del que depende el desarrollo del procedimiento ${ }^{53}$, el carácter personal y secreto del voto, la personalidad, la igualdad y la universalidad en el acceso a la votación —-la brecha digital dificulta el acceso a este sistema de voto a una parte importante de la población-. Pero, sobre todo, el mayor temor es «que el sistema falle, de que surja un problema en su aplicación y se genere entre los partidos y la ciudadanía una desconfianza sobre la pureza de los resultados electorales» ${ }^{54}$, cuyos efectos sobre la confianza en el sistema electoral y su legitimidad serían demoledores. Por último, como aspecto positivo fuera de toda duda, es preciso señalar que el voto electrónico implicaría una reducción de los costes con respecto al actual procedimiento de votación, aunque debería evaluarse el coste inicial que conlleva la adquisición del software y los elementos físicos necesarios para su implantación ${ }^{55}$.

Al margen de las consideraciones sobre el voto electrónico, el resto de las observaciones realizadas por la JEC son, en buena medida, el sustento de la previsible contrarreforma en ciernes que abordaremos a continuación en el siguiente apartado, donde se analizarán también algunas de las comparecencias de diferentes representantes de organismos públicos y colectivos, producidas en la Subcomisión parlamentaria creada al efecto para la reforma electoral y cuyos trabajos están a punto de concluir.

La contrarreforma en ciernes para paliar los perjudiciales efectos del voto rogado y propuestas de mejora:

52 GÁlvez MuÑoz, L., «Aproximación al voto electrónico presencial...», op. cit., p. 263.

53 GonZÁlez De LA GarZA, L.M., «Voto electrónico por internet y riesgos para la democracia (I)», $R D P$, n. ${ }^{\circ}$ 74, 2009, p. 174.

54 GÁlvez MuÑoz, L., Ruiz GonZÁLEZ, J.G., «El voto electrónico y el test de calidad; o de cuatro bodas complicadas y un posible funeral», RDP, n. ${ }^{\circ} 81,2011$, p. 261.

55 Ibidem, p. 267. 
Los trabajos de la Subcomisión parlamentaria, salvo nueva prórroga, están a punto de finalizar. Recientemente, se ha trasladado una propuesta a los miembros de la Subcomisión para suprimir el voto rogado y ampliar los plazos del procedimiento de forma que se facilite el envío y la recepción de la documentación electoral, pero no ha sido publicada y su literalidad se mantiene a día de hoy con carácter confidencial por los grupos parlamentarios, por lo que únicamente se han conocido algunos detalles a través de los medios de comunicación. En las informaciones publicadas, se hace mención a la supresión del voto rogado, de forma que la documentación electoral para votar se remitirá de oficio a partir del décimo octavo día posterior a la convocatoria electoral. En la documentación el elector encontrará una papeleta en blanco que deberá rellenar - esto plantea dificultades, por ejemplo, para las elecciones al Senado, con listas abiertas_-, del mismo modo a como sucedía con anterioridad a la supresión del art. 190 LOREG para las elecciones locales. Además, se pretende ampliar el plazo en dos días para votar en urna en las oficinas consulares, de forma que a partir de ahora se establecerá un plazo entre el sexto y el segundo día anterior al día de las elecciones, pero sin posibilidad de prórroga por la JEC. Por último, se pretende garantizar la gratuidad total del voto para los españoles residentes en el extranjero, habilitando apartados de correos específicos para ello. Estas medidas, a priori, cuentan con un amplio acuerdo en el seno de la Subcomisión, aunque los representantes del Grupo Parlamentario Popular han mostrado alguna reticencia al respecto.

Al margen de los aspectos cuya modificación se pretende y ante lo que no hay mucho que objetar, sí es preciso indicar que los cambios son insuficientes y carentes de ambición, más bien parches para salir del paso. En este sentido, llama poderosamente la atención la omisión, al menos por las informaciones conocidas, de facilitar a los electores españoles residentes en el extranjero la descarga de la documentación electoral de forma telemática, teniendo en cuenta además que el envío de oficio a más de dos millones de electores en el extranjero supondrá, con total seguridad, un incremento considerable de los gastos asociados al proceso electoral. Así mismo, se podría plantear la posibilidad de realizar el escrutinio en la propia oficina consular, siempre que exista un número de votos en urna suficientes como para preservar el secreto del voto (se podría establecer, por ejemplo, que en el caso de haberse emitido al menos 10 votos por urna, el escrutinio se producirá en la propia sede diplomática, del que se levantará acta, dando fe el responsable de la misma y se enviará telemáticamente a la correspondiente Junta Electoral para proceder al cómputo de los votos). En todo caso, esta forma de proceder para el escrutinio sería más coherente si se constituyera una circunscripción exterior en el futuro. En todo caso, no parece ser una medida a incorporar en la futura legislación electoral la ampliación del plazo para proceder al escrutinio general, de manera que se puedan recibir más votos emitidos en el exterior por los españoles inscritos en el CERA que, como sabemos, dependen en buena medida de los servicios postales de terceros países. 
Tampoco parece abordarse una cuestión relevante, a nuestro juicio, como es el desarrollo de las actividades propias de la campaña electoral en el exterior por las formaciones políticas concurrentes a los procesos electorales, en línea con lo sucedido con anterioridad, puesto que las diferentes reformas legislativas anteriores apenas han cambiado sustancialmente las dinámicas tradicionales de la campaña electoral ${ }^{56}$, aunque sí han contribuido a la mejora de su desarrollo ${ }^{57}$. Al haberse modificado las condiciones para el ejercicio del derecho del voto para los españoles en el extranjero, hubiera sido una buena oportunidad para haberlo hecho también con la regulación de la campaña electoral en el exterior. La ausencia de regulación en nuestro Derecho de la campaña electoral para quienes se establecen fuera de España es un aspecto negativo de nuestra legislación electoral, en tanto coloca a los españoles residentes-ausentes en clara situación de inferioridad, entre otras cuestiones, por la no recepción de información sobre las distintas opciones políticas concurrentes al proceso electoral ${ }^{58}$ en igualdad de condiciones con respecto a los electores inscritos en el CER, aunque en el Derecho comparado encontramos casos en los que se contempla restrictivamente.

Por otro lado, también resulta conveniente reforzar los recursos técnicos y humanos en las embajadas y consulados españoles en el futuro, lo que depende de la voluntad gubernamental. Pero además del necesario refuerzo, también es posible que el legislador habilite a las oficinas consulares para que asuman auténticas funciones delegadas del Censo para que puedan gestionar el envío de la correspondencia a los electores ${ }^{59}$, así como mantener una fluida relación de información sobre los procesos electorales, que también pasaría por establecer la obligatoriedad para facilitar medios electrónicos de comunicación — facilitar un correo electrónico, además de un teléfono móvil_ como requisito para mantener la inscripción en el CERA.

También, a nuestro juicio, para mejorar la representación y la participación de los españoles residentes en el extranjero, se debe considerar la creación de una circunscripción especial para los españoles residentes en el exterior. Ahora bien, para que esta opción no requiera la necesaria reforma constitucional por no respetar en sentido estricto el carácter provincial de la circunscripción electoral (artículos 68.2 y 69 CE), sería preciso forzar en exceso el texto constitucional con una ficción jurídica para aglutinar al conjunto del electorado residente en el

56 Esta opinión, en cambio, no es compartida por el prof. Aranda Álvarez, E., Estudios sobre la Reforma de la Ley Orgánica del Régimen Electoral General: la Reforma continua y discontinua, (Dirs. ÁlvarEZ Conde, E. y López De Los Mozos Díaz, A.), p. 355, IDP, Madrid, 2011.

57 La LO 2/2011 modificó aspectos relativos a la regulación de la campaña, centrándose fundamentalmente en dos cuestiones: evitar la incidencia de los poderes públicos mediante campañas de carácter institucional e inauguración de obras, y la reducción del gasto realizado por las formaciones políticas en publicidad y propaganda durante el periodo electoral —incorporación de los nuevos apartados 2 y 3 del art. 50, y cambios en los arts. 53, 54.1 y 55.3 LOREG-.

58 «El informe del Consejo de Estado sobre la reforma electoral. Texto del informe y debates académiCos», CEPC, 2009, p. 65.

59 García Mahamut, R., op. cit., p. 287. 
extranjero en una provincia adicional. Ciertamente, es difícil encontrar encaje en nuestra actual Carta Magna sin su reforma en este punto, por cuanto supone crear una nueva circunscripción electoral sobre la base de las circunstancias personales de los electores y no teniendo en cuenta el elemento territorial establecido en la Constitución. De considerarse esta opción por el legislador, sin duda, bordearía la previsión constitucional sobre la circunscripción electoral pero, en última instancia, podría encontrar cobertura si lograra adaptar de manera consecuente la legislación orgánica — conforme establece el artículo 141.1 CE—.

Esta ficción de adscribir a los residentes en el exterior a una provincia adicional no es diferente a la mecánica actual, también llena de ficción, donde se vincula a los españoles residentes en el exterior a un municipio y la provincia, a efectos de su integración en el censo electoral correspondiente. Esta opción fue objeto de análisis en el Informe del Consejo de Estado de $2009^{60}$, tomando como referencia también algunos ejemplos existentes en el Derecho comparado (Italia, Portugal y Colombia), y asegurando que sería «un medio idóneo para favorecer la implicación de los ciudadanos ausentes en la vida política de su país, al darles más peso en la toma de decisiones». El tamaño de una provincia única, adicional y especial para los españoles inscritos en el CERA sería asimilable en términos de censo electoral, a día de hoy, a provincias como Valencia; y situándose como la tercera «provincia» española con mayor censo electoral, sólo por detrás de Madrid y Barcelona. El propio Consejo de Estado en el citado informe ${ }^{61}$, encuentra una solución intermedia que no precisaría de forzar en exceso la Constitución y permitiría vincular de forma directa a los españoles residentes en el extranjero con un número de diputados a elegir. Se trataría, en este caso, de adscribir a los inscritos en el CERA a una de las circunscripciones provinciales actuales, siguiendo el sistema neerlandés. Si bien, y suscribiendo los motivos del Consejo de Estado, esta opción plantea serios hándicap insalvables tales como, por ejemplo, alterar y desvirtuar la relación entre representantes y representados de la correspondiente provincia de adscripción de estos electores, pudiendo superar en número a los que en la actualidad componen su censo electoral.

\section{PRONUNCIAMIENTOS DEL TRIBUNAL CONSTITUCIONAL}

Pese a la importante trascendencia de la modificación normativa en materia electoral y la contestación política y doctrinal posterior, tras apreciar las negativas consecuencias en la práctica que el ejercicio del voto rogado implica para la participación electoral de los españoles residentes-ausentes, apenas hay

$60 « \mathrm{El}$ informe del Consejo de Estado sobre la reforma electoral. Texto del informe y debates académicos», CEPC, 2009, pp. 97 y ss.

61 «El informe del Consejo de Estado...», op. cit., p. 99. 
pronunciamientos al respecto del TC. Ello es debido, fundamentalmente, al apoyo parlamentario en la aprobación de la Ley, con el acuerdo de los dos principales partidos políticos en las Cortes Generales de la IX Legislatura, PSOE y PP, que sumaban, entre ambos, 323 de los 350 diputados del Congreso; pero, además, esta reforma contó con el respaldo de los diputados de CiU y PNV (en total: 339 diputados favorables a la reforma para la implantación, entre otras cuestiones, del voto rogado). Pese a la oposición de otras formaciones políticas representativas, ninguna de ellas contaba con representación parlamentaria suficiente — cincuenta diputados o cincuenta senadores- para la presentación del recurso de inconstitucionalidad, por lo que el plazo para recurrir la Ley ante el TC expiró sin la presentación de recurso. Hoy en día, con la actual conformación política de las Cortes Generales, la situación hubiera sido diferente y, con cierta seguridad, es posible afirmar que, de haber sido aprobada la LO 2/2011, ésta hubiera sido objeto de recurso de inconstitucionalidad por algún grupo parlamentario que en las actuales Cortes Generales sí cuenta con representación parlamentaria suficiente.

El primer pronunciamiento cronológico del TC (STC 105/2012), después de la entrada en vigor de la LO 2/2011, tuvo lugar tras el recurso presentado por las candidaturas de IU de Asturias y el PSOE, frente a una sentencia de la Sala de lo Contencioso-Administrativo del TSJ de Asturias por anulación del recuento de la mesa electoral del censo de electores residentes-ausentes de la circunscripción de occidente. Los recurrentes en amparo solicitan al Alto Tribunal que se declaren válidos los votos de los residentes-ausentes emitidos en la circunscripción occidental de Asturias, invalidados por el TSJ que emplazó a una nueva convocatoria electoral a los electores de la correspondiente mesa por haberse dirigido una parte de estos votos a la Junta Electoral Provincial y no a la oficina o sección consular, como es preceptivo tras la reforma del art. 75 LOREG. En esta sentencia, aunque no de manera central, el TC sí declara respecto al nuevo procedimiento de voto para los residentes ausentes tras la reforma de $2011^{62}$. Más allá de esta consideración, el objeto de la sentencia del TC era otro y, en consecuencia, termina por declarar la nulidad de la sentencia del TSJ asturiano que mandataba la anulación de los votos de los residentes-ausentes puestos en duda por haber sido remitidos erróneamente a la junta electoral provincial y la repetición electoral, de modo que valida el resultado electoral y la proclamación del sexto escaño en liza de la candidatura del PSOE en la circunscripción occidental de Asturias.

El recurso de amparo ha servido en esta ocasión, en ausencia de la presentación de un recurso de inconstitucionalidad por parte de un grupo parlamentario, como vía alternativa para la interpretación o control objetivo del ordenamiento,

62 «Ha sido el legislador, en el ejercicio legítimo de la función constitucionalmente conferida ex artículos 66 y $81 \mathrm{CE}$, quien ha configurado en el extremo que ahora importa el procedimiento del ejercicio del derecho de voto por correo de los electores residentes-ausentes y que dicha configuración, no merece reproche constitucional desde la perspectiva de los derechos fundamentales en juego» (STC 105/2012, FJ 13). 
que corresponde a los órganos jurisdiccionales —en este caso, al TC - en contraposición con el control subjetivo de naturaleza política ${ }^{63}$. Ahora bien, el Tribunal Constitucional sólo puede manifestarse sobre las concretas cuestiones planteadas vía amparo, que no giraban en torno a la generalización del voto rogado para los españoles residentes en el extranjero, por lo que la falta de impulso del control político a la norma - sujeto a los vaivenes e intereses de la política partidista, esto es, que responde a razones subjetivas - ha impedido, en esta ocasión, una sentencia de interpretación objetiva sobre la adecuación constitucional del voto rogado como requisito previo para ejercer el derecho al voto en el exterior, con relación indudable con el ejercicio de derechos fundamentales. Y ello porque, en última instancia, sólo la interpretación de la ley a través de la interpretación constitucional, puede encontrar su tratamiento adecuado ${ }^{64}$.

Por otro lado, el segundo pronunciamiento del TC, esta vez sí sobre la exclusión de nacionales del derecho al sufragio tanto activo como pasivo determinada por la LO 2/2011 en elecciones locales, referido al recurso de inconstitucionalidad presentado por el Gobierno autonómico de Canarias contra varios apartados del artículo único de la citada Ley, al considerar la supresión del sufragio de los españoles residentes-ausentes en los comicios locales y a cabildos insulares, contraria al bloque de constitucionalidad y a preceptos de la propia Constitución. En su recurso, el Gobierno canario recurre la norma conectando los arts. 149.1.1 y 14 con los arts. 13.2 y 23.1 de la Constitución, apreciando desigualdad entre españoles para el ejercicio del derecho a la participación política mediante el sufragio; y la lesión de los artículos 13.1 y 23.1 en relación con el 68.5 CE, al privar del voto a los españoles residentes-ausentes en las elecciones municipales y a los cabildos insulares. El Tribunal Constitucional, en su sentencia 153/2014 desestimó el recurso de inconstitucionalidad del Gobierno canario, al no apreciar vulneración del principio de igualdad ni de los preceptos de la Constitución (FJ 3 ), infracción de las normas encuadradas en el bloque de constitucionalidad (FJ 4), ni que la extensión de la exclusión de los residentes-ausentes a participar en la elección de los cabildos insulares fuera contraria a la Carta Magna (FJ 5).

En ausencia de pronunciamiento contrario a la constitucionalidad de la Ley, no es posible asegurar a priori que la norma adolezca de este vicio. No obstante, los asuntos relacionados que han sido objeto de estudio por el TC, no han permitido entrar a conocer del fondo de la cuestión, es decir, sobre si la nueva configuración del ejercicio del derecho de sufragio por los españoles residentes-ausentes supone, en realidad, un verdadero obstáculo que impide su efectivo ejercicio. De este modo, a nuestro juicio, existen dudas razonables sobre si, en realidad, la reforma planteada por el legislador puede considerarse conforme al mandato

63 Aragón Reyes, M., «La interpretación de la Constitución y el carácter objetivado del control jurisdiccional», REDC, n. ${ }^{\circ} 17,1986$, pp. 101 y ss.

64 Ibídem, p. 120. 
constitucional del art. $23 \mathrm{CE}$, en relación con el art. $42 \mathrm{CE}^{65}$, una vez comprobado que la práctica del voto rogado limita de hecho el derecho al sufragio por los nacionales residentes-ausentes, hasta el punto de encontrar supuestos en que su ejercicio es prácticamente imposible.

\section{CONCLUSIONES}

La reforma de la LOREG de 2011, con la generalización del voto rogado, supuso un cambio sustancial en la forma en que los españoles residentes en el extranjero ejercen su derecho al sufragio activo. En su origen, la reforma fue aprobada con amplio respaldo parlamentario, e incluso desde la doctrina se consideró el voto a instancias del elector en el extranjero como medida proporcionada para solventar los problemas de fraude detectados en el pasado, catalogándose como «la mejor manera de garantizar la limpieza del voto así como que éste sea personal y que no se gestione o emita a través de terceros» ${ }^{66}$. En realidad, las consecuencias sobre la participación electoral de los españoles residentes-ausentes han sido nefastas.

La generalización del voto rogado para los españoles residentes en el extranjero, además de ser un error político, es un menoscabo del principio democrático y del principio de igualdad, así como una lesión del derecho fundamental contenido en el artículo $23 \mathrm{CE}$. El voto rogado ha tenido un efecto de desaliento ${ }^{67}$ en el ejercicio del derecho fundamental a la participación política de los españoles residentes en el extranjero. Como efecto, ha producido un incremento de la desconfianza hacia el sistema electoral, al haber obstaculizado de hecho el ejercicio del voto a centenares de miles de españoles, muchos de ellos emigrados como consecuencia de la crisis económica, que lejos de romper el vínculo con nuestro país, querían seguir manteniéndolo al menos como electores de pleno derecho. Es decir: el voto rogado ha mermado el derecho fundamental a la participación política, tanto en términos cuantitativos como cualitativos, como consecuencia directa de la acción del legislador, cuya labor no debería responder a la lógica partidista cuando se habla de garantizar el ejercicio de los derechos fundamentales, sino que debe atenerse a la lógica de los mandatos constitucionales que le obligan a remover los obstáculos para el ejercicio de todo derecho fundamental y no a introducirlos, como ha sido en la práctica, el voto rogado. Por ello, es imprescindible la aprobación inmediata

65 Ripollés Serrano, M.R., «La nueva regulación del derecho al voto de los españoles que se encuentran en el extranjero, especial consideración al CERA tras la reforma de la LOREG por la LO 2/2011», Estudios sobre la Reforma de la Ley Orgánica del Régimen Electoral General: la Reforma continua y discontinua, (Dirs. Álvarez Conde, E. y López De Los Mozos Díaz, A.), p. 201, IDP, Madrid, 2011.

66 García Maнamut, R., «La reforma electoral (LO 2/2011) y el voto de los españoles en el exterior (CERA). La inefectividad del derecho de sufragio de los españoles en el exterior. Una necesaria revisión», TRC, n. ${ }^{\circ} 30,2012$, p. 285.

67 De Domingo Pérez, T., «La argumentación jurídica en el ámbito de los derechos fundamentales: en torno al denominado 'chilling effect' o 'efecto desaliento'», REP, n. ${ }^{\circ} 122,2003$, pp. 141-166. 
de la contrarreforma que derogue el voto rogado, así como articular las medidas oportunas para garantizar de forma efectiva la gratuidad en la emisión del voto por los españoles residentes-ausentes en el extranjero.

Así mismo, el legislador debe contemplar en la contrarreforma otros aspectos procedimentales relevantes, tales como: por un lado, aumentar el plazo de días para recibir la documentación electoral y el posterior para enviar o depositar el voto y, por otro, permitir el escrutinio en las embajadas y oficinas consulares, en vez de remitir los votos a las Juntas Electorales Provinciales, aunque este aspecto debe ser regulado con cautela para que no impida mantener el secreto del voto en urnas con pocos electores, en las que también deberían introducirse los votos por correspondencia, dirigidos a las delegaciones diplomáticas habilitadas como centros de votación. El recuento de los votos recibidos - tanto por correspondencia como presencialmente en urna-, se producirá en las sedes diplomáticas bajo la responsabilidad última de los encargados de las mismas, que actuarán como fedatarios públicos de los resultados reflejados en las actas de escrutinio tras el recuento de los votos, enviadas posteriormente por vía telemática para su cómputo con el resto de sufragios escrutados en territorio nacional. Este cómputo podría unificarse en una circunscripción si se optara por la creación de una propia para computar los votos de los españoles residentes en el exterior.

El envío de oficio de la documentación electoral es, a nuestro juicio, un coste excesivo cuya eficiencia debería valorarse. La descarga telemática de la documentación electoral parece la alternativa más factible, no sólo por el ahorro en costes, sino por la rapidez para disponer de la documentación para emitir el voto, que debería hacerse en papeleta en blanco con posibilidad de indicar la opción política a la que se desea otorgar el sufragio, aunque se plantea la dificultad de que esta modalidad de voto para el caso de la elección de los representantes en el Senado. Los sobres para depositar el voto podrían ponerse a disposición en las oficinas postales - para lo que es necesaria la coordinación con los servicios de correos de los terceros países - para quienes opten por emitir su voto por correspondencia, y en las sedes diplomáticas para el caso de quienes opten por el voto en urna. Para facilitar el flujo de información en el periodo electoral, debería hacerse un esfuerzo por recabar datos de los residentes en el extranjero que permitan un contacto permanente, tales como el teléfono móvil y, sobre todo, el correo electrónico.

Ha de explorarse la creación de la circunscripción «provincial» exterior con un número fijo de escaños asignados a elegir en Congreso y Senado, si bien deben resolverse las cuestiones suscitadas en este trabajo en torno al encaje constitucional. Esta nueva circunscripción permitiría cristalizar la relevancia electoral de la población española residente en el extranjero, favoreciendo la conexión del electorado con sus representantes, aunque éstos no tengan vocación de representación particular únicamente de los intereses de los españoles en el exterior. Habría que plantear, además, como ocurre en Italia o Portugal, si a su vez es conveniente 
dividir el electorado exterior en varios distritos o zonas, para intentar corregir el desequilibrio en la distribución de españoles residentes en el extranjero.

Por último, resultaría conveniente que el legislador incorporara disposiciones acerca de las actividades de la campaña electoral realizadas en el exterior, posibilitando incrementar el límite del gasto electoral para aquellos partidos que hagan campaña en el extranjero. Así mismo, las formaciones concurrentes a las elecciones deberían poder comunicarse con los electores inscritos en el CERA a través de las delegaciones diplomáticas, que deberán remitir la información vía correo electrónico a través de los datos de contacto disponibles. Y, de articularse la creación de la circunscripción «provincial» exterior, sería oportuno facilitar la celebración de debates electorales entre los cabezas de las candidaturas que optasen a la elección de representantes por esta circunscripción, lo que permitiría incrementar el interés por el desarrollo de la propia campaña electoral, incentivaría el voto y el vínculo entre representados y futuros representantes.

En definitiva, este trabajo ha pretendido contribuir a la mejora del sistema de representación, con un debate en torno al denominado voto rogado y la práctica del mismo desde su generalización en 2011. En conexión, hemos realizado propuestas para mejorar la participación de los españoles residentes en el extranjero, con respeto a los principios democrático y de igualdad. En nuestra opinión, de no atender al menos los cambios aquí planteados, el sistema de representación permanecerá incompleto y sobre el que seguirá creciendo la desconfianza por parte de la ciudadanía, tarea que sin duda no puede ser ajena al Derecho constitucional.

$$
* * *
$$

TITLE: Implementation of 'voto rogado' in Spain: harmful limit to electoral participation of the spanish residents abroad on point of amendment

ABSTRACT: The reform of electoral legislation about the vote of Spanish citizens residing abroad has generated a political and social debate on the convenience of maintaining the so-called "voto rogado" since its approval in 2011. The legal change sought to increase the guarantees in the exercise of the right to active suffrage abroad, but it actually incorporated another obstacle in the procedure, making it difficult for Spanish residents abroad to vote. As a result, the voter turnout rates of Spanish citizens residing abroad in the electoral processes held from 2011 are lower than those registered before this reform. Recently, the Parliamentary Subcommittee for the electoral reform is debating a legal amendment to repeal "voto rogado", although there is still no unanimous agreement around the new formula for exercising the right to vote of Spanish citizens residing abroad.

RESUMEN: La reforma de 2011 de la legislación electoral, relativa al voto de los españoles en el extranjero, ha generado un debate político y social desde su aprobación sobre la conveniencia de mantener el denominado voto rogado. El cambio legal buscaba incrementar las garantías en el ejercicio del derecho al sufragio activo en el exterior, pero realmente incorporó una traba más al procedimiento dificultando la participación electoral de los españoles residentes en el extranjero. Como consecuencia, las cifras de participación de españoles en el extranjero en los procesos electorales celebrados desde 2011, son inferiores a las registradas antes de la reforma. Recientemente, la Subcomisión parlamentaria para la reforma electoral debate una modificación legal para derogar el voto rogado, aunque todavía no existe un acuerdo unánime en torno a la nueva fórmula para el ejercicio del derecho al voto de los españoles residentes en el extranjero. 
KEY WORDS: political paticipation, abroad, right to vote, elections, Democracy.

Palabras clave: participación política, extranjero, derecho de sufragio, elecciones, Democracia.

FECHA DE RECEPCIÓN: 15.06.2018

FECHA DE ACEPTACIÓN: 05.02.2019 